\title{
Renegotiating roles as part of developing collaborative practice:Australian nurses in general practice and cervical screening
}

\author{
Jane Mills' \\ Mary Fitzgerald ${ }^{2}$ \\ 'Nursing and Midwifery, Faculty \\ of Medicine, Health and Nursing \\ Sciences, Monash University, \\ Gippsland, Melbourne, Australia; \\ ${ }^{2}$ School of Nursing, Midwifery \\ and Nutrition, Cairns Campus, \\ James Cook University, Smithfield, \\ Queensland, Australia
}

\begin{abstract}
This paper reports the findings from an action research study that used a reflective group method to work with nurses in general practice recently credentialed as cervical screeners. The research aimed to develop a new model of practice nurse service delivery within a multidisciplinary team. Findings demonstrated that poor interdisciplinary collaboration created barriers to changing the role of the practice nurse. Key themes identified were: renegotiating their roles, identifying and negotiating gendered patterns of cervical screening, and the effect of multidisciplinary teams and interdisciplinary collaboration on practice nurse retention. Recommendations from this study address the need for improved piloting of new initiatives and an increase in continuing professional development for practice managers who are potential change agents.
\end{abstract}

Keywords: action research, reflective groups, Australia, practice nurse, nurse in general practice, general practice

\section{Introduction}

Against a backdrop of increased funding to general practices for the employment of nurses, the general shortage of general practitioners in Australia, and moves towards interdisciplinary collaborative models of service delivery, the potential role of the nurse in general practice is up for broader discussion and debate. The introduction of credentialing for nurses to undertake cervical screening in general practice enabled registered nurses in Queensland to assume a role that was previously the domain of medical general practitioners. How integration of this new service in general practice is negotiated in order to provide a 'win-win' situation for the multidisciplinary team has direct bearing on the potential of the new model of care to provide a template for the introduction and efficient provision of other screening procedures.

The aim of this action research study was to systematically develop a model of best practice for the introduction and maintenance of cervical screening services provided by registered nurses in a general practice setting through:

- identifying stakeholder perspectives and other factors that influence service provision and uptake in the locale;

- forming strategies, implementing them and critically reflecting on the consequences, in order to reform strategies and account for progress (cyclical process of action research);

- reporting on the implementation of the model of service delivery with recommendations for similar practice developments; and

- building participants' research capacity by enabling them to become facilitators of action research. 
This paper presents the findings from this study and discusses the lack of interdisciplinary collaboration in multidisciplinary general practice teams as exemplified in patterns of cervical screening referral by general practitioners to nurses in general practice in the Australian context. Interdisciplinary collaboration is a broad term that can be defined as a multidisciplinary approach to health care provision that recognises and incorporates the scope of practice of each professional team member to provide timely and appropriate coordinated client/patient care (Watts et al 2004). A review of the literature about collaborative practice between registered nurses and medical practitioners in Australian general practice postulates a set of critical attributes that constitute collaborative practice. Patterson and McMurray (2002) summarize these as: shared planning, goal setting, decision-making, problem-solving, and responsibility; combined with open communication characterized by cooperation and coordination - all of which are underpinned by nonhierarchical relationships demonstrating shared power and authority based on knowledge and expertise.

\section{Background}

In response to demand for reduced workforce pressure and improved access to primary care services for patients, particularly in rural areas, the Australian Government has invested heavily in general practice. The Nursing in General Practice Initiative (Porrit 2007; Price 2007) is a financial incentive scheme designed to encourage the employment of nurses in urban, rural and remote general practice that was implemented in 2001.

Since that time the Australian Government has also reviewed the role of nurses in general practice through research about: consumer perceptions, the nurse's role and the types of support structures required for their development (Cheek et al 2002; Hegney et al 2004; Watts et al 2004; Gibson and Heartfield 2005). This initial ground work has culminated in the recent publication of competency standards for nurses in general practice (Australian Nursing Federation 2005) and a revised guide to nursing in general practice aimed at the general practice team (Royal College of Nursing 2005). Both documents are an excellent guide for stakeholders, however there is a dearth of research in Australia that tests the implementation of models of practice through all phases of development and evaluation.

Legitimating the role of nurses in general practice through the provision of separate funding has come late to Australia. A high degree of autonomy in the role of the practice nurse has been an accepted part of primary healthcare in the United
Kingdom (UK) since 1990 when there was a major reform of funding arrangements for general practice (Atkin and Lunt 1996; Watts et al 2004). Since that time the number of nurses in general practice has approximately trebled, while the number of general practitioners has remained stable. General practitioners in the UK perceive four main advantages of employing nurses: 'saving the physician's time, meeting targets, extending services, and improving access for patients' (Harrison et al 2002, p. 300).

Growing consumer demand for primary health services will necessitate general practice teams in Australia, as in the UK, to become more collaborative. A collaborative or enhancement model of general practice has been identified as one of three models currently in use in Australia, the other two being a model of delegation and a model of substitution (Halcomb et al 2004). When trying to find a middle ground between substitution and delegation that best reflects collaborative practice, Patterson and McMurray (2002) advocate for a model that retains the unique elements of both medicine and nursing while identifying that there are areas that overlap. Multidisciplinary general practice teams in this model demonstrate team leadership and case management roles that are dictated by patient need and practitioner competence thereby promoting interdisciplinary collaboration. There is, however, an acknowledged gap in the literature about how such models of interdisciplinary collaborative practice between nurses in general practice and general practitioners develop particularly in cases where medically led delegation and substitution models are deeply ingrained norms (McKernon and Jackson 2001).

Cervical screening and the provision of pap smears is a priority area that is being linked to funding initiatives for registered nurses in general practice. A Medicare Benefit Scheme (MBS) item number was introduced for Australian nurses in general practice to undertake a pap smear on behalf of a general practitioner in a rural or remote area in January 2005. In November 2006 this MBS item number was extended to include pap smears and a well women's health check and was able to be accessed all general practitioners, not just those in rural and remote Australia (Porrit 2007). Previous items funded have been in the areas of: immunization, health assessments, and chronic disease management (Royal College of Nursing Australia 2005).

\section{Research design \\ Participants}

Six female registered nurses in general practice were originally recruited to undertake a pilot course of cervical 
screening education and training in 2005. Post-course supervised practice resulted in these nurses being credentialed to undertake cervical screening without the direct supervision of general practitioners, but in consultation with the general practitioner. These nurses were invited to join an action research group, which was convened in 2006.

\section{Ethical issues}

Cycles of action research enable continuous outcomes for participants as they share their stories, learn from each other, formulate actions, implement these, and then share the outcomes with the participant group. Because of the nature of action research, confidentiality was not able to be assured for participants, however in an information session prior to the study the importance of confidentiality was explained by the authors and the research group agreed to ground rules that included respect for each other and trust. Each participant has been de-identified in the final report and any other publications that have arisen from the study.

Ethics approval was sought and gained from the James Cook University Human Research Ethics Committee in January 2006. Participants signed individual consent forms prior to participating in this study and were able to withdraw their participation at any stage.

\section{Methods}

There are many interpretations of action research but Carr and Kemmis (1986), in a seminal text on action research, wrote that typically action research is concerned with a concrete problem in practice, uses a cycle of research processes, and is participatory. The action research process is designed to be responsive to changes as they occur in the experience of the participants and its rigor is in the planning, execution of plans, and critical reflection on actions or experiences to inform further plans (Carr and Kemmis 1986; Fitzgerald and Armitage 2006).

This study adopted an action research group approach as described by Winter and Munn-Giddings (2001) and Hart and Bond (1995) using the following questions as a framework:

- What else has an impact on this issue in the practice?

- How else may this problem be viewed?

- Why do others behave the way they do?

- How do I feel about this and what do these feelings tell me about what is going on?

- What else do I need to find out before making a judgment?
Participants in this action research group met one evening per month over six months. Within the action research process participants question the status quo and together plan and implement change in incremental steps. The action research group provides a space where participants are able to explore issues safely, propose potential solutions or actions, and then reflect on the outcomes from these actions.

Although six nurses were invited to join the group, only three chose to stay with the group throughout the process. In addition, the research team consisted of one division of general practice project officer and two nursing academics. The first author, who is an experienced mentor, supported the action research group through: organising meetings, facilitating democratic processes, stimulating critical reflection, collecting data, and summarizing findings for the group. She was also responsible for the drafting of reports for the collective.

The group adopted a relaxed structure to the meetings. A catch-up session accompanied by food was used to break the ice at the beginning of each meeting. When the more formal work began, a summary of the last meeting was given and people were asked to provide an update of what had been happening. The other group members largely listened to people speak, only interrupting to ask questions that might help the speaker reflect and learn from their situation.

The meetings were tape-recorded and fully or partially transcribed. The analysis of these data helped the authors to prepare summaries for the group and to unpack the situation and issues that constituted the issues of concern to the general practice nurses in the group. In the early sessions the research team used creative means to stimulate participants' reflections by making posters or scrap booking. This was dropped as the issues for discussion became clearer and conversations flowed easily. A password-protected blog site was also set up and used intermittantly by the group as a means of connection between meetings.

\section{Trustworthiness}

Methods of data generation and thematic analysis used in this critical study produced findings that are not generalizable to Australian nurses in general practice. If a theoretical argument, such as the one we make in the findings of this paper 'fits' with the reader's experience, 'works' to explain the participant's experiences, is 'relevant' to the wider field of nursing in general practice, and is 'modifiable' over time then it demonstrates a degree of trustworthiness (Glaser 1978; Sandelowski 2000; Mills et al 2007), that can be measured by the 'grab' it has for the reader. Action researchers have 
a similar view when they refer to the transferability of the account provided by the researchers and judged by readers on comprehensibility, truthfulness, sincerity, and appropriateness (Whitehead and McNiff 2006).

\section{Results}

\section{Scenario I: Nurses in general practice - renegotiating their roles}

Australian nurses in general practice are by and large employees of general practitioners, which was the case for participants in this study. In the early group meetings employment status was frequently raised as a precursor to how participants were able (or not) to negotiate changing their role.

[W] hen you look at how the system is set up, whatever we say we're employed by these people, so we're restricted... I don't think until we get a separate type of funding... we will ever be seen as peers. (Transcript 4: First Quarter).

Participants had all completed a continuing professional development program that led to them being credentialed as cervical screeners. One of the selection criteria for attendance at the program was a letter of endorsement from the practice principle (GP), however participants found that this did not always facilitate an automatic acceptance of a change in their role. Rather, their potential role as cervical screeners still had to be negotiated upon their return to the workplace.

Historically the work of nurses in general practice is task orientated with GPs delegating work in a fragmented way to their nurse assistants (Willis et al 1999). Cervical screening, however, is one task that is part of a broader well women's health care assessment that the participants had been educationally prepared to undertake. Tensions arose therefore between participants and GPs who were reluctant to refer clients to the nurses for anything more than the undertaking of the task of cervical screening. Ultimately, because of their employment status, the nurses were reluctant to contest this even though it resulted in clients not receiving 'best practice' levels of care. The view that pap smears are just a task to be delegated by GPs to nurses is reflected in the following quote:

[He said], 'if we throw one [a pap smear] your way' we can do it - but that's no good to me, I can't work, I can't do them like that, once every two months and then I don't have their support... (Transcript 4: First Quarter).

When asked in the reflective group if there was the opportunity provided, what message she would like to give to the GPs who had initially endorsed her credentialing as a cervical screener and who were now obstructing her from using this skill in the way she thought right, the nurse answered,

I would tell them... that I felt that they are letting the community, the women out there in the community down, because they're the ones that want it... And it was obvious from the ladies that I did, that they wanted it - but I can't, I can't do anymore at that practice (Transcript 4: First Quarter).

As a group, the participants reflected on what else could be impacting on GP's referral patterns that limited the role of the nurse to undertaking the task of cervical screening. A key issue identified was that the Australian Government MBS funding of cervical screening was at the time inadequate to remunerate the amount of time that a nurse would need to allocate to a structured well women's session. This led to a conflict between the general practitioner as small business owner, and the nurse in general practice who is both a primary care and primary health care provider. Well women health checks are driven by both health promotion and preventative health care and require a longer timeframe and a higher degree of autonomy in practice for the nurse, than performing a pap smear as a stand-alone task.

This process of 'putting yourself in someone else's shoes' was very useful for participants to start feeling less angry and disenfranchised and more proactive about finding a potential solution to this scenario. The group agreed that GPs needed to see the value in providing nurse-led well women's clinics before they would be able to be established and that this value would not necessarily equate with the financial remuneration received from the MBS item number.

As a place to begin renegotiating nurses in general practice's clinical role, it was agreed that a 'champion' or advocate for expanding the role of the nurse needed to be identified and enlisted. There were two reasons for this, firstly there is strength in numbers and secondly, there are people who work in general practice who are in stronger negotiating positions with practice principles than nurses.

Practice managers were identified as potential champions, playing a key role in promoting open communication and new models of practice. Participants spoke of practice managers having a role as both a translator and mediator between nurses and other practice staff, and the general practitioners for who they work.

At the end of the day they're (general practitioners seeing one point of view and you're (nurse in general practice) seeing it from another point of view. There should be somebody that looks after, umbrellas, the whole practice and says "well I understand where you're coming from, 
but [if] we're looking at best practice, offering the best service for our clients then this will work" (Transcript 4: Second Quarter).

Another potential champion identified in the general practice team were GPs who were also employed, as opposed to having a financial interest in the business. For one participant this was the case, working alongside a GP who had considerable experience in the UK where nurses in general practice routinely undertake well women's health care. Supported by this GP, the nurse was able to renegotiate her role to include a regular well women's clinic that was widely publicized within the practice with a subsequent increase in the referral rate of women requiring cervical screening.

\section{Scenario 2: Identifying and negotiating gendered patterns of cervical screening}

After the first three reflective group meetings, participants who were committed to the action research process became apparent both by their regular attendance and willingness to try different processes within the group to 'dig down' into the meaning of the stories told. As a result of asking the question 'what else is going on here?' participants identified gender as a major influence on GP's patterns of referral for cervical screening. In general practice, well women's health checks, including cervical screening, had until now been the province of female general practitioners. It took time for the participants to work through this issue of gender, trying to understand why female GPs appeared to be so resistant to nurses in general practice broadening their role to include a task that was 'theirs'. The politics of how female GPs were prioritized over nurses for client referral was also very marginalizing for the participants, with many of these decisions being made behind the closed doors of the doctor's meetings.

The first thing that I got was feedback from the practice manager ... they decided at a doctor's meeting ... [that] when anybody rang, the receptionist was not allowed to give them the opportunity of me (the nurse in general practice) they were [only] allowed to tell them a female GP would do a pap ... [I]f a male doctor didn't want to do it [cervical screen] ... then the patient ... could be given the opportunity of me or the female doctor (Trancript 4: Fourth Quarter).

Pringle's argument that women doctors hold more marginal positions in medicine, which leads to them 'turning their gender into an advantage rather than a disadvantage' (Pringle 1998, p. 194) where possible is visible here. Interestingly in this scenario, the male GP still reserved the right to choose between the nurse and their female GP colleagues reinforcing the marginalized position the female GPs held in this practice. In response to this story, the group asked 'why do others behave as they do?' working through how the female general practitioner might be feeling about nurses performing a task that they saw as part of their role, with one participant saying,

I think it's because they've probably come in late even when you think about it historically they've [been] so many male GPs, probably when they came up and did their training that [cervical screening/well women checks] was one area that they could keep to themselves or champion themselves so you know suddenly maybe we're doing the next thing which is knocking on their door and they think it's their territory. (Transcript 4: Fourth Quarter).

This is understandable. However, while women may well prefer to have a female undertake cervical screening, it is a service that is equally well provided by nurses, freeing doctors to provide other services to their clientele. The government has chosen to endorse this practice by nurses in order to increase the uptake of cervical screening and to provide a new choice of service for patients. If female GPs want to continue to provide this service to clients even when there is a nurse available they should negotiate and argue their role from the clients' perspective as opposed to it being their right as a clinician.

Having identified gendered patterns of cervical screening referral, the participants felt disempowered in the face of trying to negotiate directly with female GPs who would not refer clients to them and showed little interest in understanding the potential change to their role.

...[O]ne of the female doctors [said] "Oh ...by the way how are your paps going?" ... I said "Not very well ... I'm not given the opportunity to do them" ... so she says "Well okay when I ... have some that I'm doing today I'll call you in ... so you can watch" I said, "Well that's not going to help me one little bit is it" (Transcript 4: Fourth Quarter).

The strategy devised by the group was the same as for negotiating their role more generally: finding a champion who had a different power relation with the female GP who was creating a barrier to change. Such a strategy equates to a virtual silence by the nurse in the face of a doctor blocking the development of their practice. This lack of power and control in groups that include professions other than other nurses has long been recognized as symptomatic of an oppressed group (Roberts 2000), however in this scenario it was a pragmatic response aimed at achieving a particular end. The participants also 
decided they needed to forge relationships with the female GPs and find space for more professional conversations in which they would use questioning techniques to uncover the female GPs views and open discussions about their complementary roles.

\section{Scenario 3: Multidisciplinary collaboration and retention of practice nurses}

Maintaining knowledge and skills acquired prior to employment in general practice as well as gaining and using new knowledge and skills were paramount to the level of job satisfaction experienced by participants and in turn influenced their decision to stay in general practice nursing. Two of the participants' experiences of not being able to broaden their nursing role to include well women's health screening led them to reconsider their current employment with one nurse deciding to seek a new position elsewhere. During this process the participant clearly expressed at interview her scope of practice and employment expectations.

I went through four interviews, two said that nurses wouldn't be doing pap smears in their surgery ... and ... the job I started, he was very, very keen to have the nurse do pap smears (Transcript 2: First Quarter).

The reflective process used in this action research group enabled a growing confidence in the participants to think about and look for models of general practice that demonstrate elements of interdisciplinary collaboration, such as referral pathways, nurse-led clinics, and open communication. Together the group asked the hard questions such as 'what is a collaborative relationship?' and 'what makes a team?' while reflecting on their own experiences. For the participant who decided to change jobs her report back to the group members after beginning in her new role is interesting with its emphasis on the prioritisation of space, privacy and communication. The importance of a private space for the provision of nursing care in general practice is identified in a recent study of the roles of Australian nurses in general practice (Australian General Practice Network 2006).

I have my own consulting rooms, I've got space, I have my own desk, my own bed ...my own computer. I have the ECG [and]... a cupboard for my pap smear stuff and my immunisation stuff ... there's privacy, whatever I'm doing I've got total privacy... [and the] practice manager [said at interview]... that we are family here, a team... everybody helps each other, you know if we see that you're snowed under we will stop seeing patients and help you out and ... if you see that we're in strife out there, just help out ... all that was spoken about in the interview (Transcript

2: Fourth Quarter).

The strategy devised by the participants was to critically reflect on their skills and potential contribution and to negotiate with the practice players [in either the current practice or a new one] a way of being able to work together.

\section{Discussion}

Findings from this study demonstrate that interdisciplinary collaboration is currently a myth for this group of nurses in general practice in Queensland. A lack of collaboration adversely influenced cervical screening referral patterns to these nurses thereby limiting their practice. Policy and funding shifts that have enabled an expansion of the nurse's role to include tasks such as cervical screening have not taken into account the traditional positions that general practitioners and nurses in general practice assume in their daily lives. These positions are dominated by the internal power relationships of small business owners/employers and paid employees who need to earn their way, and which currently distort and obstruct multidisciplinary collaboration between professionals working together in general practice (Halcomb et al 2005). Nurses identifying champions who are in a different position of power in relation to practice principles and who will support a change in their role can facilitate renegotiating their role. Seeking support in numbers and from GPs with previous experience working with nurses who had a broader role in delivering primary care in a preventative health framework was a successful strategy developed in this action research study.

Critical thinking by nurses about interdisciplinary collaboration in multidisciplinary teams is beginning to influence the retention of, and access to, a highly skilled and responsive nursing workforce for general practice. New nurses in general practice often come from the acute care sector looking for a professional challenge that embraces an extension of their role and the utilization of skills that they may bring from other areas. As well, Australian Government initiatives have led to an explosion in the numbers of nursing positions in general practice (Porrit 2007), which means experienced nurses in general practice can now afford to take into account a variety of factors when thinking about their current and future employment.

Participants in this study were conscious of the impact of nursing workforce shortages on an increasing demand for nurses in general practice. Generally nurses look towards general practice for employment because of the flexibility of hours and the ability to work on a part-time basis. Pascoe 
and colleagues (2005) found that $84.7 \%$ of nurses working in general practice do so on a part-time basis. This same study also found that continuing professional development was increasingly important for participants, with $94.9 \%$ having undertaken ongoing study in the past two years. As well, $65.9 \%$ of participants had some post-basic formal qualification. This evidence is supported by the profile of participants in this study and reflects their priorities in their working lives. To improve retention rates of new and novice nurses in general practice, there needs to be a recognition of the importance of using the breadth of the nurse's experience in order to improve levels of job satisfaction and ultimately to provide more and better choices for consumers of primary health care in Australia.

Participants in this study demonstrated that nurses in general practice often work in a traditional model of care provision that includes task delegation by medical practitioners. Coming together in an action research group supported some members' levels of confidence and skills in negotiating a change in their role as cervical screeners. Finding a 'champion' from within the ranks of their medical colleagues was a pragmatic response to managing within a traditional medical model. Outcomes from these negotiations were a change in their role and scope of practice to include well women's health checks, including cervical screening. Such an process is supported by the findings of Halcomb and colleagues (2005) who argue that commonly the scope of practice of nurses in general practice is highly variable and defined by negotiation, as opposed to a clear career pathway.

Even though general practice is positioned alongside other primary care service models, such as family planning services, where nurses are successfully employed to provide well women health checks as a part of their role (Christie et al 2005), barriers were identified for participants who wished to expand their role which can be attributed to context and culture. In particular, the genderization of medicine and the role of the female general practitioner was found to impact greatly on the ability of practice nurses to change their role to incorporate cervical screening, traditionally seen as a the business of female doctors.

A final outcome from the action research group process was the formulation of a set of questions for general practice teams to ask themselves (Table 1) prior to implementing a new model of care/service delivery. Each of these questions aim to improve communication within multidisciplinary teams in order to promote interdisciplinary collaboration, part of which is a clarification of team members' roles and responsibilities.
Table I Questions for general practice teams prior to implementing a new model of care/service delivery

I. To what extent are the new nursing services viewed as an economic initiative and/or a client-centered service? What are the consequences of that view on service delivery?

2. What opportunities are there in this practice for formal and informal multiprofessional discussion and strategic planning?

3. How has this service (cervical screening in this instance) been provided in the past? Who will be most affected by this change? How do these people feel about nurses undertaking this role? How are they going to adjust together to provide a client-centered service?

4. What will be different about this service? What resources will be needed to ensure nurses can provide this service?

5. How will the team know that the initiative is successful?

6. How will members of the team maintain their competence and knowledge in this area of practice?

Research with nurses in general practice has several barriers that need to be acknowledged and provided for when designing a research study such as this. Davies and colleagues $(2002$, p. 371) report 'that practice nurses are mostly female, often work part-time, and frequently attempt to combine paid and unpaid work' limiting the time that they have to contribute to research. Such gendered working patterns make participating in research more difficult and unless the benefit for the participant outweighs the cost the retention rate of participants is uncertain. As well, practice nurses relative inexperience in research, lack of exposure to research studies and a lack of funding for research specific positions also provide barriers (Yallop and McAvoy 2007). Action research is an appropriate research methodology for such a participant group because rather that adding research to their work it provides them with support to work (Koch and Kralik 2006).

\section{Study limitations}

Classically the findings from this study are limited by the sample size and the nature of data generation and analysis. Methods such as those used in this study, however, are dependant on the quality of the participation rather than the number of participants. Action research studies are often left unpublished because numbers of participants dwindled as the initial burst of enthusiasm wears off. The participants in this study who stayed the course contributed a great deal and learnt much and we believe their deliberations and the knowledge generated are worthy of dissemination. While the experiences of participants described are not generalizable to all Australian nurses in general practice we would argue that the purpose and intent of this action research 
study was to stimulate change and provide information for others to consider and adopt with due regard for their local circumstances. Time allocated to the project appeared to be generous however radical change of this nature cannot be forced and the project is by no means finished. The learning of the action research processes of critique and dialogue are an important outcome that will sustain the clinicians when the group disbands.

\section{Recommendations}

Decisions made at a political level, such as providing funding for cervical screening to be performed by Australian nurses in general practice do not necessarily transition smoothly into clinical practice. Findings from this study demonstrate that the existing culture of general practice needed to be considered prior to implementing such a 'top down' policy approach in order to maximise the potential benefits to clients. Piloting the implementation of new MBS item numbers prior to their introduction could potentially identify any existing barriers and associated strategies to overcome these. Policy makers need to be cognisant that the ad hoc introduction of MBS item numbers to potentially meet an identified need is only one part of the process of culture change that will make changes in clinical practice operational and ultimately improve client outcomes.

Participants in this action research study identified the importance of practice champions who were able to transgress the power structures that existed between GPs and nurses. Practice managers are ideally placed to assume this role of promoting open dialogue between members of the multidisciplinary general practice team with the aim of promoting interdisciplinary collaboration. The capacity of practice managers to do this however is dependant on their experience and learnt ability. Continuing professional development opportunities that focus on managing change, promoting teamwork and facilitation could be helpful in achieving this goal.

\section{Conclusion}

Clearly this small action research study has implications for practice development. Australian nurses in general practice have the potential to expand their role in the provision of primary health care, and funding policy is changing to account for this. However, there needs to be more careful consideration of the implications of the ad hoc introduction of a variety of MBS item numbers on the structure and functioning of current multidisciplinary teams. Promoting interdisciplinary collaboration in Australian general practice is possible but to effect this level of cultural change, barriers need to be identified along with strategies to overcome these prior to introducing new initiatives.

\section{Acknowledgments}

Dr Jane Mills gratefully acknowledges that a Primary Health Care Research Education and Development Fellowship, James Cook University, School of Medicine, Townsville Campus facilitated this research study. The authors report no conflicts of interest.

\section{References}

Atkin K, Lunt N. 1996. Negotiating the role of the practice nurse in general practice. $J A d v$ Nurs, 24:498-505.

Australian General Practice Network. 2006. Australian General Practice Nurses Study Phase 1. Canberra, Australian General Practice Network.

Australian Nursing Federation. 2005. Competency standards for nurses in general practice. Australian Nursing Federation.

Carr W, Kemmis S. 1986. Becoming critical: Education, knowledge and action research. Melbourne: Routledge.

Cheek J, Price K, Dawson A, et al. 2002. Consumer perceptions of nursing and nurses in general practice. Adelaide, University of South Australia, Consumer Perspectives and Department of General Practice Adelaide University.

Christie L, Gamble J, Creedy D. 2005. Women's views of registered nurses as Papanicolaou smear providers: A pilot study. Contemp Nurse, 20:159-68.

Davies J, Heyman B, Bryar R, et al. 2002. The research potential of practice nurses. Health Social Care Commun, 10:370-81.

Fitzgerald M, Armitage D. 2006. Clinical research: the potential of practice development. Pract Dev Health Care, 4:150-9.

Gibson T, Heartfield M. 2005. Mentoring for nurses in general practice: an Australian study. J Interprof Care, 19:50-62.

Glaser B. 1978. Theoretical sensitivity: Advances in the methodology of grounded theory. Mill Valley: Sociology Press.

Halcomb E, Davidson P, Daly J, et al. 2005. Nursing in Australian general practice: directions and perspectives. Aust Health Rev, 29:156-66.

Halcomb E, Davidson P, Daly J, et al. 2004. Australian nurses in general practice based heart failure management: implications for innovative collaborative practice. Eur J Cardiovasc Nurs, 3:135-47.

Harrison S, Dowswell G, Wright J. 2002. Practice nurses and clinical guidelines in a changing primary care context: an empirical study. J Adv Nurs, 39:299-307.

Hart E, Bond M. 1995. Action research for health and social care. Philadelphia: Open University Press.

Hegney D, Price K, Patterson E, et al. 2004. Australian consumers' expectations for expanded nursing roles in general practice: Choice not gatekeeping. Aust Fam Phys, 33:845-8.

Koch T, Kralik D. 2006. Participatory action research in health care. Oxford: Blackwell Science.

McKernon M, Jackson C. 2001. Is it time to include the practice nurse in integrated primary health care? Aust Fam Phys, 30:610-15.

Mills J, Francis K, Bonner A. 2007. Live my work: rural nurses and their multiple perspectives of self. $J$ Adv Nurs, 59:583-90.

Pascoe T, Foley E, Hutchinson R. 2005. The changing face of nurses in Australian general practice. Aust J Adv Nurs, 23:44-50.

Patterson E, McMurray A. 2002. Collaborative practice between registered nurses and medical practitioners in Australian general practice: Moving from rhetoric to reality. Aust $J$ Adv Nurs, 20:43-8.

Porrit J. 2007. Policy development to support nurses in general practice: An overview. Contemp Nurse, 26:56-64. 
Price K. 2007. Nurses in general practice: Roles and responsibilities. Contemp Nurse, 26:7-14.

Pringle R. 1998. Sex and medicine. Cambridge: Cambridge University Press.

Roberts S. 2000. Development of a positive professional identity: Liberating oneself from the oppressor within. Adv Nurs Sci, 22:71-82.

Royal College of Nursing. 2005. Nursing in general practice: A guide for the general practice team [online]. Accessed on May 12, 2008. URL: http://www.rcna.org.au/UserFiles/screenrez.pdf.

Sandelowski M. 2000. Combining qualitative and quantitative sampling, data collection and analysis techniques in mixed-method studies. Res Nurs Health, 23:246-55.
Watts I, Foley E, Hutchinson R, et al. 2004. General practice nursing in Australia. Canberra: Royal Australian College of General Practitioners and Royal College of Nursing, Australia.

Whitehead J, McNiff J. 2006. Action research living theory. Sage: Thousand Oaks.

Willis E, Condon J, Litt J. 1999. Working relationships between practice nurses and general practitioners in Australia: a critical analysis. Nurs Inquiry, 7:239-47.

Winter R, Munn-Giddings T. 2001. A handbook for action research in health and social care. London: Routledge.

Yallop J, McAvoy B. 2007. The research potential of practice nurses: What contribution to primary health care research? Contemp Nurse, 26:117-24. 
